\title{
Influence of the Photoinitiator Concentration on the Mechanical and Optical Properties of Dental Resins
}

\author{
Daniel de Melo Faleiros ${ }^{a}$, Carla C. Schmitt ${ }^{a}$ Miguel G. Neumann ${ }^{a *}$ (D) \\ ${ }^{a}$ Universidade de São Paulo, Instituto de Química de São Carlos, São Carlos, SP, Brasil.
}

Received: April 20, 2021; Revised: July 28, 2021; Accepted: August 4, 2021

\begin{abstract}
The dependence of the photoinitiator concentration on the degree of conversion, mechanical properties and colour appearance of dental materials was studied. Alterations due to changes in the concentration of the photoinitiator were-undertaken. Test samples prepared by photopolymerizing BisGMA and TEGDMA in the presence of the photoinitiator camphorquinone (CQ) were prepared and submitted to mechanical analyses, i.e., compressive and diametral tensile strength and Barcol hardness tests and CIELAB colour analysis. The hardness and compressive tests showed a levelling off at concentrations around $0.5 \%$ and remained at those values up to $1.0 \%$, whereas the DTS didn't show any variation over that range of concentrations. The colour experiments showed dependence with the concentration of $\mathrm{CQ}$ in the photopolymerizing system due to its intense absorption in the yellow region. The results indicate that photopolymerization systems containing $\mathrm{CQ} / \mathrm{EDB}$ as photoinitiator at concentrations between 0.5 and $1.0 \%$ present similar mechanical properties.
\end{abstract}

Keywords: Dental materials, photoinitiators, camphorquinone, compressive strength, diametral tensile stress, Barcol hardness, CIELAB analysis.

\section{Introduction}

Dental materials research has been constantly evolving in order to make clinical interventions faster, less error-prone, more painless, and also turning restorations more durable and aesthetically similar to the natural structures of teeth. In the current stage of development, to ensure the aesthetics and durability of dental restorations, properties of the used dental materials, such as solubility, infiltration resistance, chemical stability, stability to temperature variations, compatibility with pulp tissue, surface roughness, color, translucency, fracture toughness, fracture resistance, fatigue resistance among others, have been studied.

Thus, there are several studies aiming to determine the factors that impact the color and mechanical strength of dental resins. By instance, Furuse et al. ${ }^{1}$ studied the influence of the reducing agent, Oliveira et al. ${ }^{2}$ and also Silami et al. ${ }^{3}$ determined the variation of those properties as a function of different photoinitiators submitted to various LED-light wavelengths, whereas Randolph et al. $^{4}$ and Ilie et al. ${ }^{5}$ evaluated the influence of various irradiation processes on those properties. In general, it was found that mechanical hardness properties, as well as optical properties vary according to the photoinitiator and reducing agents used to promote light curing.

Dental resins are composites containing a polymeric matrix (usually based on dimethacrylates), inorganic reinforcement fillers load (usually quartz-based or silicates), and coupling agent to promote the bond between the reinforcement load and the polymeric matrix (usually derived from silane $)^{6}$. Most of the materials consist of at least two dimethacrylate monomers: BisGMA (Bisphenol A glycidyl dimethacrylate) and TEGDMA (triethyleneglycol dimethacrylate). The photopolymerizable resins contain in their formulation, in addition to a combination of fillers and monomers, one or more photoinitiators to promote the photopolymerization reactions.

Photoinitiators are compounds that, under irradiation (generally in the visible or near UV region), produce chemical species that will initiate the polymerization process. In some cases, an additional compound is necessary to complete this process, called co-initiator. One of the most used photoinitiators is camphorquinone (CQ). The mechanisms involved in the photopolymerization of dental resins by this initiator is well-known and requires a co-initiator, usually an amine derivative like ethyl-4-dimethylaminobenzoate $(\mathrm{EDB})^{7,8}$.

One of the factors that haven't been evaluated so far, is the effect of the concentration of the photoinitiator on the mechanical and optical properties of the dental resins. In the present study these effects were evaluated for resins obtained by photopolymerization of BisGMA / TEGDMA in the presence of different concentrations of the camphorquinone/ ethyl-4-dimethylaminobenzoate photoinitiator.

\section{Experimental}

\subsection{Materials}

The test samples were obtained by photopolymerization of a bisbiphenol A-glycidyl dimethacrylate [BisGMA 
98\%, Sigma-Aldrich, structure $(a)$ ] and triethyleneglycol dimethacrylate [TEGDMA 95\%, Sigma-Aldrich, structure $(b)$ ] mixture. The photoinitiators was a mixture of camphorquinone [CQ 98\%, Fluka, structure (c)]. The co-initiator was ethyl-4dimethylaminobenzoate (EDB 99\%, Sigma Aldrich). Chemical structures of the used materials are shown in Scheme 1.

\subsection{Test samples}

Samples were prepared by photopolymerizing 50-50 w/w mixtures of BisGMA and TEGDMA. The mixtures were kept under agitation at $25 \pm 5^{\circ} \mathrm{C}$ for $24 \mathrm{~h}$ prior to polymerization, in order to obtain a homogeneous mixture. The photoinitiator system CQ/EDB was added to obtain CQ proportions of $0.01,0.1,0.25,0.5,0.75,1.0$ and $10 \% \mathrm{w} / \mathrm{w}$. The amount of the co-initiator EDB was always kept at $1 \%$.

The mixtures contained in a cylindrical glass tube ( $\sim 4 \mathrm{~mm}$ diameter, $\sim 5 \mathrm{~cm}$ length) were irradiated on the upper side of the tube with a $3 \mathrm{M}^{\mathrm{TM}}$ ESPE ${ }^{\mathrm{TM}}$ DeepCure LED $\left(1200 \pm 200 \mathrm{~mW} / \mathrm{cm}^{2}\right)$ for about $160 \mathrm{~s}$. Maximal conversions of $35-40 \%$ were obtained after irradiating for $30 \mathrm{~s}$. The cylindrical polymer was then cut to obtain $2 \mathrm{~mm}$ height discs for DTS tests and $8 \mathrm{~mm}$ for compression tests. Afterwards, the discs were kept for $24 \mathrm{~h}$ at $37^{\circ} \mathrm{C}$ in distilled water to simulate the oral conditions ${ }^{9}$. Discs cut from different cylinders showed no noticeable difference among them.

Polymerization rates and conversion were evaluated by the RT-FTIR (real time FTIR) technique using a Fourier Transform Infrared Spectrometer (Perkin-Elmer, mod. Frontier). Absorptions at $815 \mathrm{~cm}^{-1}$ (due to the $\mathrm{C}==\mathrm{C}$ double bond and $1054 \mathrm{~cm}^{-1}$ corresponding to the $\mathrm{C}=\mathrm{O}$ carbonyl group were compared during irradiation. The conversion $\alpha$ was calculated using

$\propto=\left\{1-\left(\frac{A_{815 ; t}}{A_{815 ; t_{0}}} x \frac{A_{1054 ; t_{0}}}{A_{1054 ; t}}\right)\right\}$ were $A_{0}$ and $A_{t}$ correspond to the initial and any time absorptions at the indicated frequencies.

\subsection{Compressive and diametral tensile strength tests}

The samples for the determination of mechanical resistance were done according to standard 27 of ADA/ANSI ${ }^{10}$, as well as ISO $4049^{11}$ procedure for dental polymer-based restorative materials. Determination of the mechanical properties were performed on a Instron 5966 Universal Mechanical Test equipment (Tecsistem, Brazil) using a load cell of $10 \mathrm{kN}$ at a speed of $1 \mathrm{~mm} / \mathrm{min}$. Experiments were performed at $25^{\circ} \mathrm{C}$ and results with different samples were analysed using the ANOVA and Tukey methodologies.

\subsection{Hardness tests}

Hardness tests were performed following the ASTM D2583 ${ }^{12}$ standard. on $2.5 \mathrm{~mm}$ thickness and $6 \mathrm{~mm}$ height resin discs. Temperature and humidity were kept at $23 \pm 2{ }^{\circ} \mathrm{C}$ and $50 \pm 10 \%$, respectively.

\subsection{Colour analysis}

The CIELAB system based on the $L^{*} a * b *$ space was used to analyse the differences in colour of the resins due to the use of various concentrations of photoinitiators. A Colour i7 spectrophotometer (X-Rite) was used to determine the $L * a * b *$ parameters of $1.0 \pm 0.1 \mathrm{~mm}$ thickness resin discs. The experimental values were obtained directly from the equipment using the NETPROFILE software installed in the instrument.

\section{Results}

\subsection{Photopolymerization}

Figure 1 shows the uv-spectra of the system used to prepare the samples with different CQ concentrations. It can be noticed that the absorption peak at $\sim 475 \mathrm{~nm}$<smiles>C=C(C)C(=O)OCC(O)COc1ccc(C(C)(C)c2ccc(OCC(O)COC(=O)C(=C)C)cc2)cc1</smiles>

(a)<smiles>C=C(C)C(=O)OCCOCCOCCOC(=O)C(=C)C</smiles>

(b)<smiles>CC12CCC(C(=O)C1=O)C2(C)C</smiles> 
increases steadily as expected for larger concentration of the photinitiator. On the other hand, at shorter wavelengths there is an increase of the absorption starting at $350 \mathrm{~nm}$ for the resin components without photoinitiator. This absorption increases sharply when CQ is added to the system.

The photopolymerization is rather fast, and after about $15 \mathrm{~s}$ the maximum conversion is reached at $35-40 \%$. It is noteworthy to notice that the maximum percentage of conversion, as well as the conversion rate, are practically equal for all photoinitiator concentrations used. In these experiments, the limiting step in the photopolymerization process is the formation of the initial free radicals, that depend on the light intensity. Therefore, independent of the photoinitiator concentration, the amount of free radicals formed will always be the same (see Figure 2).

\subsection{Mechanical tests}

Table 1 shows results of the compression resistance, and diametral tensile tests for the materials obtained using different concentrations of the photoinitiator. All shown values were obtained applying the ANOVA test to, at least, four independent measurements for each system.

As can be seen, there is a relatively large dispersion of the results. Nevertheless, in general, the compression resistance decreases with the increase of the concentration of photoinitiator. On the other hand, the diametral tensile pressure seems not to be influenced at large by the photoinitiator concentrations. Barcol hardness presents an initial increase followed by a plateau.

\subsection{Colour tests}

Table 2 shows the results for the CIELab colour tests. The values shown were obtained applying the ANOVA test to, at least, four independent measurements for each system.

\section{Discussion}

\subsection{Compression}

Figure 3 shows the results of the compression tests as a function of photoinitiator concentration.

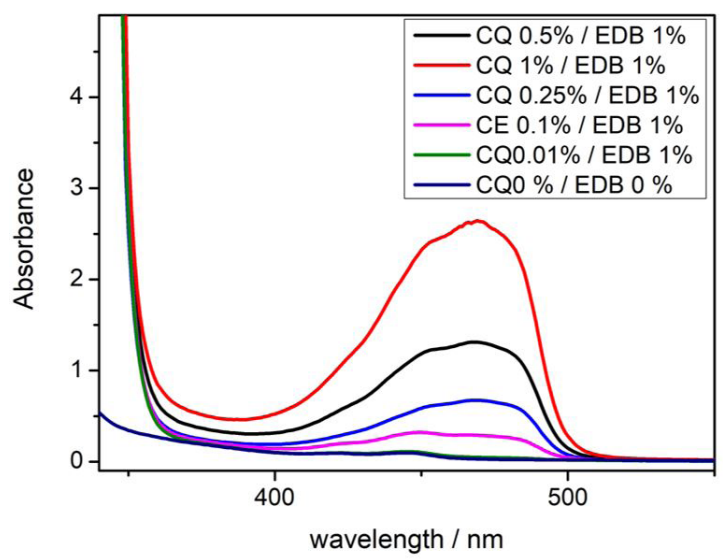

Figure 1. Absorption spectra of the photopolymerizing systems with increasing amounts of CQ.
As can be seen in Figure 3, there is a gradual decrease of the compression resistance from about $250 \mathrm{MPa}$ for the lower concentration down to around 150-160 MPa. These values are near to those determined for contemporary composite resins ${ }^{13}$.

This decrease can be attributed to the fact that the photochemical initiation process will produce a more homogeneous amount of free radicals along the sample, whereas higher photoinitiator concentrations, due to the higher absorption of light, will establish a gradient of free radicals in that direction. This distribution will produce a less homogeneous polymer that might make it less resistant to compression along the vertical axis.

\subsection{Diametral tension stress}

Figure 4 shows the results of the diametral tension stress tests as a function of the photoinitiator concentration.

The use of different CQ/EDB concentrations does not affect substantially the resistance to diametral tension, remaining more or less constant around $55 \mathrm{MPa}$.

From the comparison between the resistances to compression and to diametral stress, it can be observed that the resistance to compression is quite larger than that to diametral tension, as can be seen in Figure 5.

The bottom red line indicates the maximum pressure done on the teeth during mastication ${ }^{14,15}$. The upper limit red line indicates the minimum resistance limit of the analysed systems towards compression ${ }^{16,17}$.

Table 1. Compression resistance, diametral tensile resistance (DTS) and hardness results for samples obtained using different concentrations of the CQ.

\begin{tabular}{cccc}
\hline $\begin{array}{c}\text { \% CQ/ } \\
\text { EDB 1\% }\end{array}$ & $\begin{array}{c}\text { Compression / } \\
\text { MPa }\end{array}$ & DTS / MPa & $\begin{array}{c}\text { Hardness / } \\
\text { Barcol }\end{array}$ \\
\hline $\mathbf{0 . 0 1}$ & 225.9 & 52.09 & 30.8 \\
\hline $\mathbf{0 . 1 0}$ & 149.0 & 56.09 & 50.2 \\
\hline $\mathbf{0 . 2 5}$ & 177.7 & 56.65 & 55.6 \\
\hline $\mathbf{0 . 5 0}$ & 168.3 & 57.28 & 56.3 \\
\hline $\mathbf{0 . 7 5}$ & 154.3 & 54.14 & 55.4 \\
\hline $\mathbf{1 . 0 0}$ & 149.1 & 58.36 & 55.7 \\
\hline
\end{tabular}

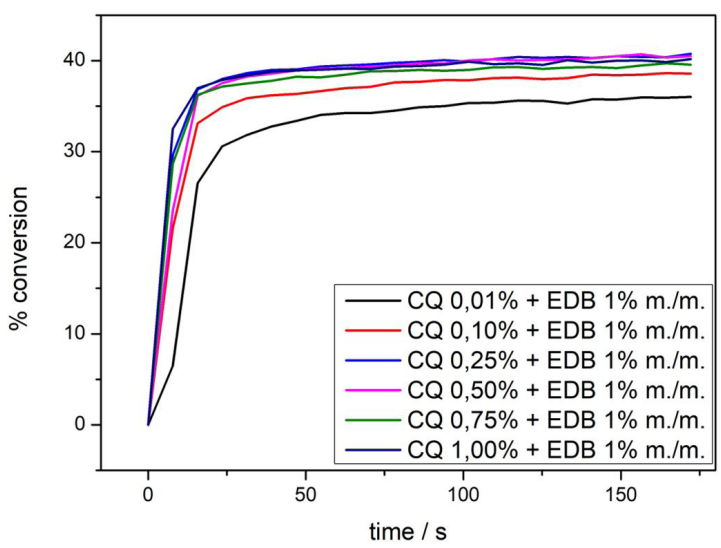

Figure 2. Conversion percentagem as function of irradiation time for systems containing different concentrations of CQ. 
Table 2. Colour data of samples obtained using different proportions of CQ in the CQ/ EDB 1\% photoinitiator system.

\begin{tabular}{|c|c|c|c|c|c|}
\hline $0.01 \%$ & $0.10 \%$ & $0.25 \%$ & $0.50 \%$ & $0.75 \%$ & $1.00 \%$ \\
\hline \multicolumn{6}{|c|}{$\left(L^{*}\right)$} \\
\hline 94.53 & 94.12 & 91.65 & 91.75 & 91.63 & 92.42 \\
\hline 93.86 & 94.02 & 91.18 & 91.86 & 91.05 & 91.92 \\
\hline 94.27 & 94.17 & 90.24 & 92.02 & 91.52 & 89.54 \\
\hline 94.19 & 93.70 & 92.78 & 91.00 & 91.63 & 91.45 \\
\hline \multicolumn{6}{|c|}{$\left(a^{*}\right)$} \\
\hline-1.24 & -1.54 & -3.43 & -3.42 & -4.20 & -4.93 \\
\hline-1.29 & -1.57 & -3.30 & -3.02 & -4.36 & -4.29 \\
\hline-1.33 & -1.47 & -2.50 & -3.51 & -4.19 & -4.10 \\
\hline-1.39 & -1.59 & -3.76 & -3.20 & -4.29 & -3.72 \\
\hline \multicolumn{6}{|c|}{$\left(b^{*}\right)$} \\
\hline 6.03 & 8.07 & 26.4 & 27.72 & 32.21 & 37.52 \\
\hline 6.11 & 10.55 & 27.9 & 25.41 & 35.31 & 35.71 \\
\hline 6.25 & 8.98 & 28.99 & 23.77 & 32.47 & 39.9 \\
\hline 6.53 & 10.71 & 22.17 & 26.27 & 30.19 & 31.92 \\
\hline
\end{tabular}

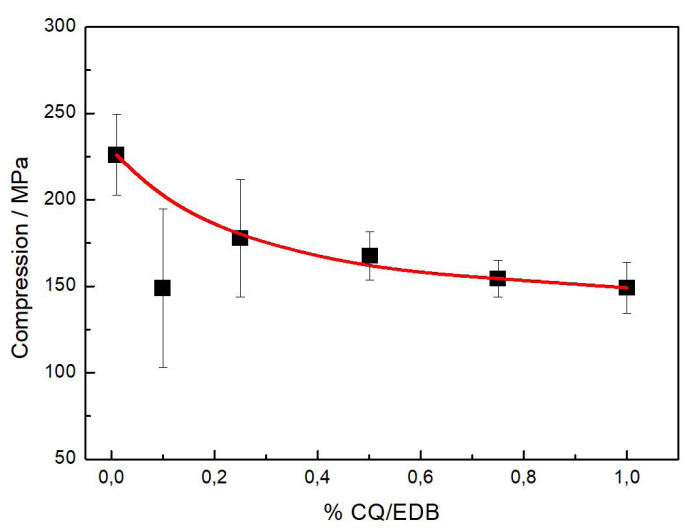

Figure 3. Compressive strength of samples obtained using different concentrations of the photoinitiator.

\subsection{Barcol}

Figure 6 shows the behaviour of the Barcol hardness as a function of the photoinitiator concentration.

As shown in Figure 6, the hardness reaches a limiting value of 50-55 in the Barcol scale at concentrations of about $0.25 \%$ of the photoinitiator. This value can be compared with those obtained for ceramic materials (85-95 Barcol) and for dental resins with ceramic components, which are generally over $70 \mathrm{Barcol}$. Also, the hardness of dental adhesives is in the range of 40-70 Barcol $^{18,19}$.

These materials, especially those obtained using concentrations above $0.5 \%$ of the photoinitiator can, therefore, be used as adhesives, as it is the restorative resin that confers the resulting resistance and hardness after the restoration procedure.

Another point that merits attention is that the values shown in the Table 1 and analysed thereafter correspond to measurements made on the side of the sample that was

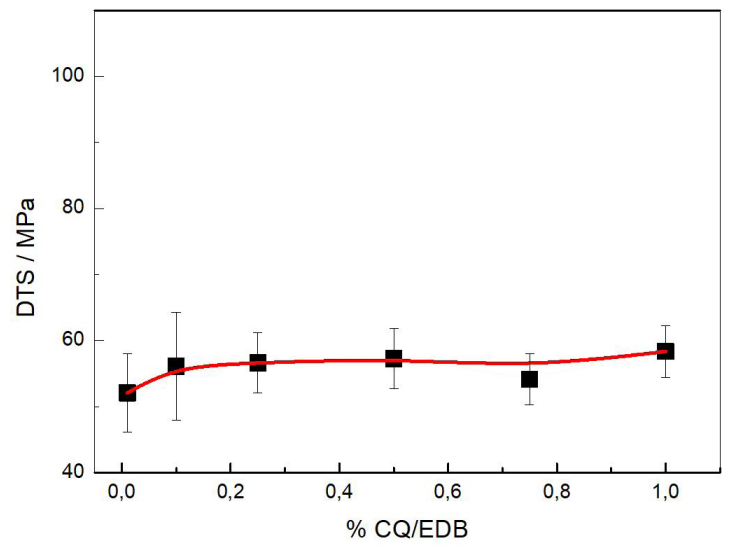

Figure 4. Diametral Tensile Stress of samples obtained using different concentrations of the photoinitiator.

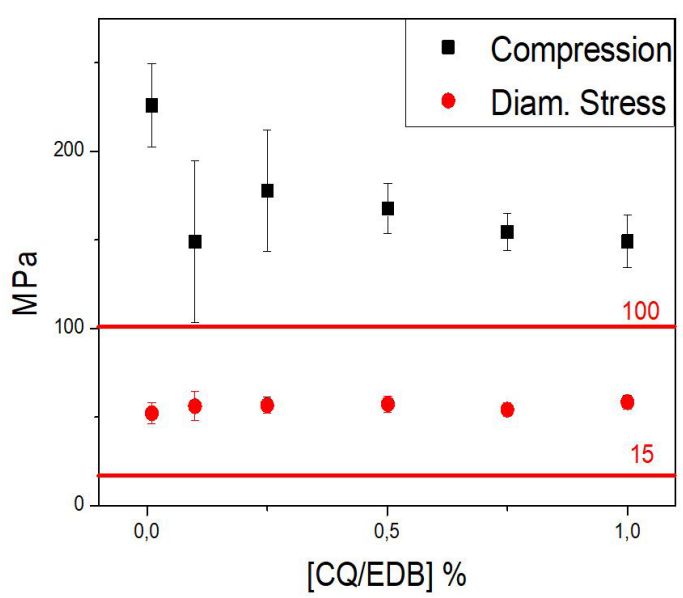

Figure 5. Comparison of the resistance to compression and to diametral stress. 
submitted to light during the polymerization process. For some of the lower photoinitiator concentrations tests performed on the opposite end ( $2.5 \mathrm{~mm}$ from the illuminated side) the hardness was somewhat lower. This effect can be traced to the fact that the photopolymerization at the opposite end could be lower due to the lower intensity of light reaching the material at that point. Therefore, a gradient of hardness could be expected for some samples. A similar effect was found by Moreira da Silva et al. who assumed a lower crosslinking density at the bottom of polymer matrixes ${ }^{20}$.

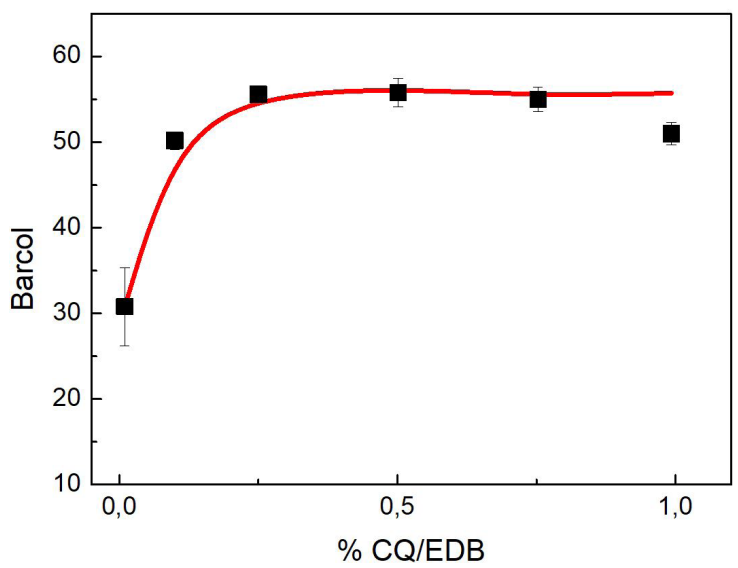

Figure 6. Barcol hardness of the samples obtained using different concentrations of $\mathrm{CQ}$ in the CQ/EDB photoinitiator system.

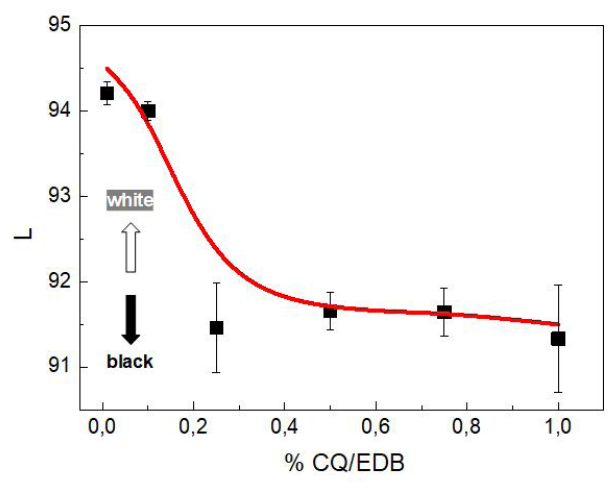

\subsection{Colour}

Although several studies were performed to evaluate the colour changes of dental resins as a function of the polymerization process ${ }^{21}$ or after its use $\mathrm{e}^{22}$, there are no investigation of how the concentration of the photoinitiator affects these parameters.

The evaluation of the colour changes was performed using the CIELab colour parameters $L^{*}, a^{*}$ and $b^{*}$. In the threedimensional space, $L^{*}$ (lightness) defines the darkness of the material, ranging from black $\left(L^{*}=0\right)$ to white $\left(L^{*}=100\right)$. The $a^{*}$-value represents the green $\left(a^{*}<0\right)$ to red $\left(a^{*}>0\right)$ components, whereas the $b^{*}$ axis represents the blue $\left(b^{*}<0\right)$ to yellow $\left(b^{*}>0\right)$ components $^{23}$. In Figure 7 the behaviour of the three parameters as function of the photoinitiator concentrations is shown.

It can be observed from the graphs in Figure 7 that there is a marked difference in behaviour between the samples prepared with increasing concentrations of camphorquinone, corresponding to a larger darkening $\left(L^{*}\right)$ and yellowing $\left(b^{*}\right)$. The lightness falls by about $4 \%$ when increasing the amount of camphorquinone up to $1 \%$. Similarly, the yellowing of the samples prepared with camphorquinone increase from 5 to 35 in that photoinitiator interval. Although there might be an increase of these parameters due to the formation of oxidized species during the polymerization process, this effect is due mainly to the use of increasing amounts of CQ/EDB because of its high spectral absorption in the blue region.

The overall colour perception can be evaluated using the $\Delta \mathrm{E}$ parameter defined by Mokrzycki and Talol ${ }^{24}$ as

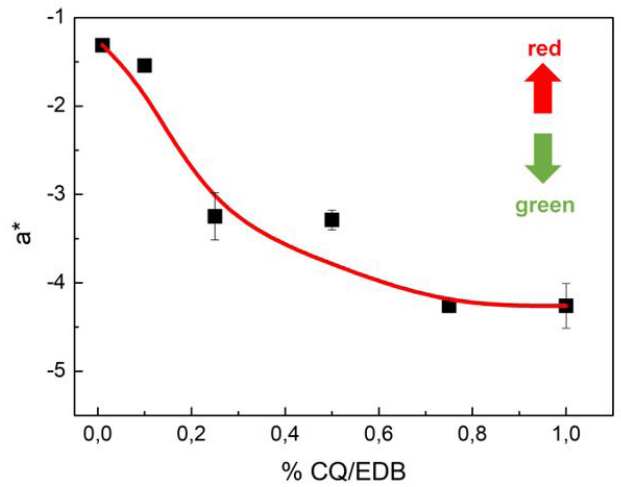

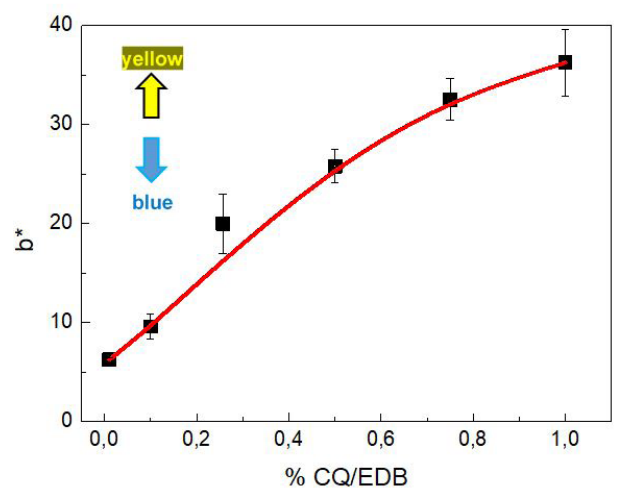

Figure 7. Behaviour of the CIELab parameters $\mathrm{L}^{*}, \mathrm{a}^{*}$ and $\mathrm{b}^{*}$ of the samples obtained using different concentrations of CQ in the CQ/ EDB photoinitiator system. 
Table 3. Colour perception parameters for increasing CQ concentrations in the photoinitiator system.

\begin{tabular}{|c|c|c|c|c|c|c|c|c|}
\hline$[\mathrm{CQ}]$ & 0.10 & & 0.25 & & 0.50 & & 0.75 & 1.00 \\
\hline$L$ & 93.9 & & 92.3 & & 91.7 & & 91.6 & 91.5 \\
\hline$a^{*}$ & -1.5 & & -3.0 & & -3.8 & & -4.2 & -4.3 \\
\hline$b^{*}$ & 10 & & 17 & & 25 & & 32 & 36 \\
\hline$\Delta \mathbf{E}$ & & 7.3 & & 8.1 & & 7.0 & & \\
\hline$\Delta E$ (rel. to 0.10$)$ & - & & 7.3 & & 15.3 & & 22.8 & 26.3 \\
\hline
\end{tabular}

$$
\Delta E=\sqrt{(\Delta L)^{2}+\left(\Delta a^{*}\right)^{2}+\left(\Delta b^{*}\right)^{2}}
$$

The corresponding values calculated from the graphs in Figure 5 are shown in Table 3.

As can be seen in Table 3, there is a constant increase of the $\Delta \mathrm{E}$ for increasing concentrations of the photoinitiator. According to Mokrzycki and Talol ${ }^{24}$ clear differences in colour are detected for $\Delta \mathrm{E}$ values larger than 3.5. Thus, Table 3 indicates that colour differences will be noticed for each photoinitiator concentration increasing step. Additionally, it can also be seen that the $\Delta \mathrm{E}$ relative to the lower concentration increases steadily, for the higher concentrations the difference is lower, possibly due to the fact the difference between these concentrations is by a factor of $25 \%$, whereas for the two initial concentrations it is $150 \%$. These features reinforce the proposal that the change in colour is due mainly to the increase of concentration absorbing in the blue region.

\section{Conclusions}

The rate of photopolymerization of the BisGMA / TEGDMA systems seems to be independent of the amount of CQ used, at least in the $0.1-1.0 \%$ region. Also the maximum amount of polymerization reached with all those proportions of the photoinitiator are similar at about $30 \%$.

The increase of the proportion of CQ in the photoinitiator system of BisGMA / TEGDMA dental resins has different effects on the mechanical properties. Whereas there is no noticeable effect on the diametral tensile resistance, the compression resistance and the Barcol hardness showed a dependence for CQ proportions between 0.1 and $0.5 \%$. At higher proportions, up to $1.0 \%$, the values remain constant at values compatible with those found for other dental systems.

On the other hand, behaviour of colour perception, as determined by the CIELab system, shows a steady increase of the yellow $\left(b^{*}\right)$ and lightness $\left(L^{*}\right)$ parameters when increasing the proportion of photoinitiator, due to the strong yellowing effect of CQ.

\section{Acknowledgments}

CCS and MGN thank CNPq (Conselho Nacional de Desenvolvimento Científico e Tecnológico) for research fellowships (Proc. 308880/2019-6 and 304716/2019-7, resp.).

This study was financed in part by the Coordenação de Aperfeiçoamento de Pessoal de Nível Superior - Brasil (CAPES) - Finance Code 001.

\section{References}

1. Furuse AY, Mondelli J, Watts DC. Network structures of BisGMA/TEGMA resins in DC, shrinkage-strain, hardness and optical properties as a function of reducing agent. Dent Mater. 2011;27:497-506.

2. Oliveira DCRS, Rocha MG, Gatti A, Correr AB, Ferrance JL, Sinhoreti MA. Effect of different photoinitiators and reducing agents on cure efficiency and color stability of resinbased composites using different LED wavelengths. J Dent. 2015;43:1565-72.

3. Silami FDJ, Mundim FM, Garcia LFR, Sinhoreti MAC, Piresde-Souza FCP. Color stability of experimental composites containing diferente photoinitiators. J Dent. 2013;41:e62-6.

4. Randolph LD, Palin WM, Watts DC, Genet M, Devaux J, Leloup G, et al. The effect of ultra-fast photopolymerization of experimental composites on shrinkage stress, network formation and pulpal temperature rise. Dent Mater. 2014;30:1280-9.

5. Ilie N, Kessler A, Durner J. Influence of various irradiation processes on the mechanical and polymerization kinetics of bulk-fill resin based composites. J Dent. 2013;41:695-702.

6. Ferrance JL. Resin composite - State of the art. Dent Mater. 2011;27:29-38.

7. Neumann MG, Schmitt CC, Ferreira GC, Corrêa IC. The initiating radical yields and the efficiency of polymerization for various dental photoinitiators excited by different light curing units. Dent Mater. 2006;22:576-84.

8. Kolczak U, Rist G, Dietliker K, Wirz J. Reaction mechanism of monoacyl- and bisacylphosphine oxide photoinitiators studied by 31P-, 13C-, and $1 \mathrm{H}-\mathrm{CIDNP}$ and ESR. J Am Chem Soc. 1996;118:6477-90.

9. Aguiar DA, Silveira MR, Ritter DE, Locks A, Calvo MCM. Avaliação das propriedades mecânicas de quatro cimentos de ionômero de vidro convencionaisnutilizados na cimentação de bandas ortodônticas. Rev Dent Press Ortodon Ortop Facial. 2008;13:104-11.

10. ADA: American Dental Association. ANSI: American National Satandards Institute. Resin based filling materials. Vol. 1. Chicago: ADA; 1993. Standard no. 27.

11. ISO: International Organization for Standardization. ISO/TC 106/SC 1. Dentistry-polymer-based restorative materials (ISO 4049). 4th ed. Geneva: ISO; 2009.

12. ASTM: American Society for Testing and Materials. D 2583 - 13a Standard test method for indentation hardness of rigid plastic by means of a Barcol impressor. West Conshohocken: ASTM; 2013. p. 1-4.

13. Nicholson J, Czarnecka B. Composite resins. In: Nicholson J, Czarneck B. Materials for the direct restoration of teeth, New York: Woodhead Publ; 2016. p. 37-67.

14. Wroe S, Ferrara TL, McHenry CR, Curnoe D, Chamoli U. The craniomandibular mechanics of being human. Proc Biol Sci. 2010;277:3579-86.

15. Zhang YR, Du W, Zhou XD, Yu HY. Review of research on the mechanical properties of the human tooth. Int J Oral Sci. 2014;6:61-9.

16. Namura $Y$, Takamizawa $T$, Uchida $T$, Inaba $M$, Noma $D$, Takemoto T, et al. Effects of composition on the hardness of orthodontic adhesives. J Oral Sci. 2020;62:48-51. 
17. Scougall-Vilchis RJ, Hotta Y, Yamamoto K. Examination of six orthodontic adhesives with electron microscopy, hardness tester and energy dispersive X-ray microanalyzer. Angle Orthodontic Journal. 2008;78:655-61.

18. Chung KH. The relationship between composition and properties of posterior resin composites. J Dent Res. 1990;69:852-6.

19. Galvão MR, Rabelo Caldas SGF, Bagnato VS, Souza Rastelli AN, Andrade MF. Evaluation of degree of conversion and hardness of dental composites photo-activated with different light guide tips. Eur J Dent. 2013;7:86-93.

20. Moreira da Silva E, Poskus LT, Guimarães JGA, Barcellos AAL, Fellows CE. Influence of light polymerization modes on degree of conversion and crosslink density of dental composites. J Mater Sci Mater Med. 2008;19:1027-103.

21. Roja RJS, Sriman N, Prabhakar V, Minu K, Subha A, Ambalavanan P. Comparative evaluation of color stability of three composite resins in mouthrinse: an in vitro study. J Conserv Dent. 2019;22:175-80.

22. Çelik EU, Aladağ A, Türkün LS, Yilmaz G. Color changes of dental resin composites before and after polymerization and storage in water. J Esthet Restor Dent. 2011;23:179-88.

23. International Commission on Illumination. CIE 15: Technical Report: Colorimetry. 3rd ed. Wien, Austria: CIE; 2004. p. 16.

24. Mokrzycki WS, Talol M. Color difference Delta E - A survey. Mach Vis Appl. 2011;20:383-411. 